\title{
In memoriam: Silvano Adami
}

\author{
M. L. Brandi ${ }^{1}$
}

Published online: 9 May 2016

(C) International Osteoporosis Foundation and National Osteoporosis Foundation 2016

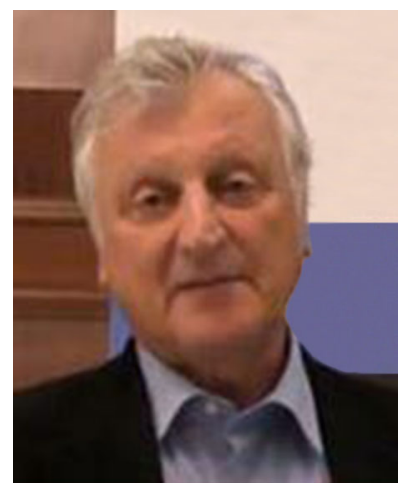

It is with great sadness that we have to inform you that Silvano Adami, Professor of Rheumatology and Chief of the Rheumatology Unit at the University of Verona in Italy, died on Saturday 26 March 2016 at the age of 69 after a long and courageous battle with cancer. Italy has lost a most creative and distinguished scientist.

A beloved, caring teacher and clinician, Silvano Adami was a world-renowned expert in osteoporosis and metabolic bone disorders. He became a full professor of rheumatology in 2005 and had been Director of the Rheumatology Unit at the Hospital of Valeggio since 1995. This hospital, part of the University of Verona, became soon thereafter a centre of

This obituary was published simultaneously in Osteoporosis International and Archives of Osteoporosis.

M. L. Brandi

marialuisa.brandi@unifi.it

1 Metabolic Bone Diseases Unit, Department of Surgery and Translational Medicine, University of Florence, 50134 Florence, Italy excellence for metabolic bone disorders, well recognized throughout Italy.

Silvano Adami was a master of irony and loved good, critical science discussions, but also took pleasure in coaching and mentoring junior faculty members. Students loved and respected him. He treated patients with care, while offering new diagnostic and therapeutic disease management. His patients will all miss him.

A 1972 MD graduate at the University of Verona Medical School cum laude, Silvano Adami qualified in internal medicine in 1977 and in endocrinology and metabolism in 1978 at Padua University with first-class honours. From January 1979 to September 1981 he was a Research Fellow at the Department of Medicine of Middlesex Hospital in London, under the mentorship of Professor J.L.H. O'Riordan. He subsequently became a lecturer in rheumatology, internal medicine, endocrinology and metabolism, and skeletal neoplastic diseases in a range of departments at the University of Verona. This wide exposure to different aspects of clinical medicine represented the grounds on which his profound knowledge of bone metabolism was built.

His colleagues and pupils will remember him as a passionate man who loved to spend time outdoors biking, skiing, traveling and swimming with his wife and children. He was also a wine connoisseur with his own wine cellar. But he will be remembered as a generous mentor with an extraordinary talent for inspiring his colleagues to excel and as a brilliant scientist and clinician. Professor Maurizio Rossini, his senior collaborator at the University of Verona, notes "Silvano supported his students and colleagues through their career to become successful specialists, not only as a model but as a father, teaching them the values of loyalty and dialogue, and strongly suggesting to spice every working day with enthusiasm in order to make great accomplishments in research". 
Silvano Adami and his colleagues developed new therapies to cure osteoporosis, collaborating with researchers all over the world. He devoted a large portion of his time to training a generation of physicians in the conduct of clinical trials. He was one of the founders of the Italian Society of Osteoporosis and served as a consultant for governmental agencies. From 2002 to 2011 he served as a member of the board of the International Osteoporosis Foundation. Through his efforts the Italian government accorded more attention to the problem of osteoporosis.

But his interests also spanned the area of rare skeletal disorders, where he was able to develop two novel treatments, registered under an orphan indication in Italy, for osteogenesis imperfecta and for algodystrophy. He provided expertise from his extensive experience with bone and mineral metabolism, offering hope through his research results. Certainly, his Renaissance mind would have had the potential for other important discoveries in neglected areas.

Silvano Adami will always be held in high esteem by all who knew him. A dedicated colleague, he will be remembered by many whose lives he touched and it is with enormous sadness that the International Osteoporosis Foundation has to say goodbye to a great colleague and foremost leader. His untimely death leaves a gap in the national and international osteoporosis community, and our thoughts are with his family and pupils at this very sad time. 